\title{
Designing innovative open spaces for learning
}

\author{
Anetta Zielińska ${ }^{1 *}$, Evgenya Romanova $^{2}$, Svetlana Tolstikova $^{2}$, and Svetlana Reshetina $^{2}$ \\ ${ }^{1}$ Wroclaw University of Economics and Business, Komandorska str. 118/120, 53-345 Wroclaw, Poland \\ ${ }^{2}$ Moscow City University, 4 Vtoroy Selskohoziajstvenny proezd, 129226, Moscow, Russian Federation
}

\begin{abstract}
Today, innovative learning spaces represent much more than just removable furniture and open spaces for workers. The digital revolution in business and education fostered by the rapid development of Internet-based tools and solutions and Information and Communication Technologies (ICT) brought about profound changes to this sector. The aim of this research is to carry out large-scale, cross-site studies to measure the current impact of ICT on working practices. Our research develops and presents the new models of learning in open spaces as well as tests how ICT can be used to support innovation and work practices. In this paper, we also single our and describe the necessary prerequisites and skills that are associated with the specific ICT functionalities that are presently needed for the entire open innovation process. Our results can be of a special use for educators, innovators, entrepreneurs as well as relevant stakeholders operating in business or education (or, perhaps, both). This research outlines the most useful recommendations and described the patterns for innovations in learning in novel open spaces.
\end{abstract}

Keywords: open space; innovation, information technology.

\section{Introduction}

Nowadays, innovative open spaces for learning represent something more beyond the sitting order or gadgets. They include collaborative software, mobile apps, video conferencing platforms, virtual reality kits and augmented reality kits that provide students and teachers with the tools for personal and shared physical space [1,2]. Classroom design can redefine interconnectivity by creating unconstrained, technology-rich environments in which students and teams can solve problems and innovate in their homes, classrooms, and communal spaces. With the increasing complexity of our world, school design has become more rational, with an emphasis on utility and longevity. For example, some schools are transforming computer rooms, libraries and outdoor spaces into flexible learning environments [3,4]. These rooms have several functions and can serve several grades in the course of a day. Some schools have created innovative outdoor learning spaces for students, including gardens and mini-ecosystems ephemeral for science learning. In some classrooms, open-air learning environments are designed for teaching, presentations, or independent group work, and can offer a new perspective to students who spend most of the school day indoors [5].

\footnotetext{
*Corresponding author: anetta.zielinska@ue.wroc.pl
} 
Generally, novel learning spaces offer a variety of educational zones. Given the context, these spaces can fit into any school, from enclosed to open learning spaces. This might contain an array different ways teachers and schools can create innovative learning environments [6].

Today, educators believe learning spaces should support social and cognitive experiences that reflect the school's educational philosophy. Many schools are built on the approach developed by Reggio Emilia in Italy in the 1940s where students play an active role in learning. This approach demonstrated how the imaginative learning spaces could be utilized at schools and how learning environments worked for teachers [7].

Furthermore, many modern universities make a good example of an informal learning environment, and given the nature of today's education one might suggest exploring the new ideas and developing opportunities [8]. In order to promote cooperation, a learning environment should be planned.

There are many ways to improve classrooms around the world to maximize the learning experience for students and teachers. Having students teach outside the traditional classroom at all times can lead to better bonding and greater enjoyment of educational activities. Design teams in the education sector have the task of developing new strategies for school construction. Today, there is a strong trend towards building Innovative Learning Environments (ILEs) in new and converted schools. An innovative learning environment is a learning environment in which classrooms and corridors are open to a diverse and activityoriented learning space [9]. This includes designing spaces based on the characteristics of the students and the tasks to be performed. It stresses the importance of adapting learning spaces to the needs and ideas of students.

Innovative learning spaces must take into account students' personal skills to ensure that they become round and productive. In traditional methods of education, pupils followed teachers, but today pupils are more responsible for their own learning and teachers are seen as guides to facilitate their own learning needs [10]. When a room in a school is an open space with lots of people, it can be difficult to focus on certain tasks such as reading. Repeatedly redesigning the classroom over the course of a day can attract students' attention and enable a variety of tasks. Blended learning models use multiple learning modes and need spaces designed to support the many different modalities that may occur: digital media, small interactive groups, peer-to-peer and teacher-led. Instead of monopolizing learning through large groups with direct instruction, we need a cellular classroom with rows of desks focused on a single teacher, as in traditional schools. The ideal is a space that supports multiple learning modes located in the same physical space, minimizing interference in the space between modes as students move between different activities.

\section{Enabling spaces for collaborative knowledge creation innovation}

Recently, Peschl and Fundneider [11] developed the entire innovation paradigm as a systematic innovation process approach, which is now called "emerging innovation". Comparing this process with traditional approaches to innovation and knowledge creation, it becomes clear that it goes beyond traditional out-of-the-box thinking and creative tools [12]. These changes require a dynamic representation of innovation as a knowledge process. In order to understand the design of innovation processes, one must first understand the underlying knowledge processes. Having these in mind, we need to keep track of how innovation and knowledge processes develop over time. It is a difficult task for an organization or a company to characterize its knowledge and innovation processes and to plan for them as such [13]. One might ask why it is necessary to understand these processes in this way at all. 
Although the focus of this research is on the front end of innovation and the process of knowledge generation, the authors are aware of the fact that in order to create knowledge and innovation it is necessary to have a successful market area for the exploitation of newly created knowledge. We attempt to design a space-based process for collaborative knowledge generation and innovation. Our research is a theoretical paper on the role of new technologies as enablers of new knowledge. Thence, we aim to discuss the impact of entrepreneurial innovation on the various collaborative and inclusive environments that give rise to innovation practices. We want to clarify the role of the various collaborative and inclusive environments and practices for innovation emerging worldwide in contexts, processes and outcomes that foster innovation and entrepreneurship. We encourage input from academics studying the impact of these environments on innovation development and commercialisation processes for young entrepreneurs.

In general terms, entrepreneurial innovation is related to the challenges of developing new products and services, structuring new organizations and commercializing them [14]. The creation of profound changes through new knowledge is a central challenge in knowledge management. Creating spaces for profound cognitive change through innovation and loss of knowledge. Knowledge and technology management to foster innovation enables collaborative co-innovation. Innovation and knowledge processes can be a confusing and complex task for companies. Organisations striving for innovation must keep a wide range of knowledge in mind throughout the innovation process $[15,16]$.

Here, it is important to outline the challenges that inspire us to develop knowledge cubes. The practical implications of the first are that new forms of work and participation require a review of evaluation and evaluation procedures and processes. To achieve this, we need to develop effective cultural assessments and use innovative assessment measures to determine the use of user paths and formal and informal groupings. Quantitative surveys can make it difficult to assess the impact of these changes on the perception of visitors and staff in open spaces and third-party spaces, which do not provide respondents with opportunities to identify specific places that mean something to them. It is impossible for an organization to reconcile such processes, objectives, and instruments without thinking through several subprocesses. As a result, the concept of an "enabling space" is often introduced as a space designed to facilitate and facilitate processes of collaborative knowledge generation and innovation $[17,18]$.

\section{Role of information and communication technologies in innovation}

One measure of technological advancement, the ICT Development Index Ranking, compares the levels of ICT use and access in different countries of the world. The top 30 countries in the ranking are high-income countries where quality of life is above average, including countries in Europe and other regions such as Canada, Japan, Macao, China, New Zealand, Singapore and the United States, while the countries surveyed improvement their ICT development index ranking every year [19, 20].

Since ICT affects daily life, it affects macroeconomic growth, which in turn affects society by improving infrastructure and living standards. The learning objective is to examine the role of technology as the driver of competitive advantages and innovations in the business environment. The key point here is that innovation is the primary source of competitive advantages for companies in the industrial environment which promotes efficiency, productivity, differentiation and the fulfilment of a variety of needs [21]. Technology is the driving force and enabler of innovation, and it is a powerful driver for the development and dissemination of innovation. Technology builds on itself and enables innovative approaches to the evolution of technology. ICT fosters innovation by improving the exchange of 
information and the dissemination of knowledge without generating innovation. ICT is a key factor for collaboration in research and innovation without increasing the costs of a single inventor or a single business model [22]. ICT facilitates global cooperation and the dissemination of knowledge due to the geographical proximity of issues and, in particular, the acquisition of tacit knowledge that cannot be codified and shared through interactive personal relationships. ICT can help reduce the costs of innovation activities in a number of ways. Cloud computing is just one example of where companies can adopt a pay-as-you-go model for computing resources without making significant investments in ICT infrastructure and software [23]. ICT access to broadband enables services to be traded, giving businesses access to lower-cost input services and reaching global markets. Managed service providers (MSPs) need to focus on taking on additional business from existing customers and offering additional types and levels of service to increase their revenue and profit margins. This raises the question of which factors enable, inhibit or support functioning innovations. Key strategies need to be further developed to meet the challenges of the increasing use of information and communication technologies. Restrictions on business process restructuring as an approach to changing work practices are particularly pronounced in ICT projects in the health sector, and ICT is evidenced by the large number of reported failures in large innovative IT projects. Evidence that ICT supports and drives innovative changes in work practice is weak and derives from non-transferable case studies of individual organisations. Many studies have shown that characteristics of teams and organizational culture are associated with effective ICT use, but are less likely than other significant factors. Literacy and mathematics lessons with ICT in combination with writing and learning produce better results than traditional methods of ICT alone [24]. UNESCO publication on ICT in education explains how organisations can be positioned in this area. Acquiring access to ICT is important not only for education, but also for power [25].

Sustainability and respect for the environment are high on the priority list for individuals, consumers, governments and organisations, but ICT offers a two-sided argument. Technologies and services in the fields of computers, data management, telecommunications and the Internet deal with the transmission and reception of all kinds of information. Information and communication technologies permeate all aspects of life and offer people a fast way to interact, network, seek help, access information and learn [26]. Because of its presence, ICT is of immense economic importance. For example, between 1981 and 2004, India and China developed national innovation systems to invest in research and development, with particular emphasis on patenting high-tech services for export. During this period, both countries experienced high GDP growth by linking the science sector to the business sector and by importing technology, thereby stimulating innovation [27, 28]. This is a good example for other countries to follow.

\section{Innovation as a highly challenging social epistemological process}

People who promote capitalism regard socialism as innovation and expend a lot of energy working against it. Some researchers perceive the spread of social innovation as an attack on money and banks [29, 30]. Social innovation in socialism and communism is the nationalization of cooperatives and associations. Once selected projects, collaborations and events have been identified in the first step, the organisation of the innovation process is reconstructed in the second step. The next step is then based on the knowledge-based framework conditions' assessment and analysis [31].

In line with the purpose of this research, the development of a semi-structured analysis is related to the vision of already established concepts of social innovation and attempts to 
transfer the concepts proposed by authors to represent new challenges degraded by the economic dynamics of today's society.

They are categorized and measured according to five dimensions: input factors for the innovation process, process outputs, impact of innovation on output, measures of access to process activities and availability of factors that facilitate the process. One needs to examine the characteristics of social innovation that contribute to its success and unpack the challenges of research in the context of the communities that drive it. We believe that research must serve the community and that social innovation requires an approach to innovation designed to balance the rigors of reality with the work of responding to community-oriented requirements. We also present proposals for practices that researchers and social innovators can use to build and sustain cooperation. The creation and design of solutions is not a new phenomenon, but technological advances and increasing globalization have enabled major leaps in the scope and impact of solutions. Health, education and environmental sustainability are ripe for innovation. Innovation is increasingly seen as a driver of competitiveness in Europe and the global market, leading to all sorts of political efforts to eliminate the rules and regulations that limit the capacity of economic operators to innovate. Innovative companies like Apple and Google are celebrated as scientists and artists of the past, instilling a lifestyle where the status quo is challenged, limited and accepted from the start. The idea of industrialized countries is that long-term growth of companies is from their ability to develop and produce innovative products and services [32]. On the other hand, the economic paradigm of technological innovation is at odds with the great challenge of global warming. Global warming is considered to be responsible for environmental degradation, resource degradation and impoverishment of populations around the world despite the imperative of economic growth [33]. In practice, the focus has been on how innovative responses are generated and disseminated, often to the detriment of emerging peripheral institutions. Many studies using diffusion innovation theory in the field of public health, for example, have focused on behavioural theory, focusing on messages of adaptation at the individual level and the use of means of change to influence innovation and act as potential users.

Critical theory is crucial to work on health justice, because it calls on scientists to recognize the extent to which prioritization of certain methods and epistemological skills in public health sustains or exacerbates the health inequalities that require health, health care, and health behaviour to be defined, understood, and evaluated in accordance with prevailing ideologies and norms. In addition to the fundamental paradigmatic differences discussed above in ontological and epistemological assumptions, interpretative and positivistic research differ in several respects. Many positivist researchers consider interpretative research to be flawed and biased, given the subjective nature of the qualitative data collection and interpretation processes used in this research. The failure of many positive techniques to generate interesting insights and new knowledge has since caused a resurgence of interest in interpretation since the 1970 s, but the precise methods and strict criteria to ensure the reliability and validity of interpretative conclusions [34].

This refers to other levels of the architecture of multi-level innovation systems (e.g. subnational, supranational, transnational). In several contexts, the networks offered here represent the predominant organizational approach that links and combines the knowledge production. At the overall level, as a national innovation system as whole, the hybrid and dynamic knowledge co-evolution between various modes (universities and university subunits on one hand and commercial and academic enterprises and fixed sub-units on the other) will unfold and will drive the next steps towards the promotion of knowledge society, knowledge economy and knowledge democracy [35]. Universities and higher education systems is a concept and metaphor that emphasises the presence and coexistence of different types of knowledge and different paradigms of knowledge. The second way is to take into account the social and organizational processes that produce innovation. In this mode, 
innovation is the goal, and it is pursued as a social process with compelling social implications. This orientation presents many challenges to public health, in particular accessibility and sustainability of health innovations for vulnerable populations. This article provides theoretical and epistemological guidance for the development of innovative socialecological strategies to promote health justice.

\section{Conclusions and final remarks}

Overall, it seems that designing innovative open spaces for learning needs the support the design and implementation of clearly defined technical artifacts, be it the introduction of knowledge-based solutions or design units. Most projects do not produce novel artefacts, but instead require a process or procedure for deploying and using novel artifacts in a problematic context. This process is a novel use of artifacts and describes effective methods for using these artifacts in problem solving. Artifacts act as other resources for building and evaluating new designs. Projects retrieve artifacts from the prescriptive knowledge base and use them in its process to create new artifacts. Definition of an innovation system as a set of components with causal relationships that influence the generation and use of innovations and innovative performance. One can find a comprehensive framework for the organisation. The term "innovation ecosystem" is a subset and a synonym for innovation system. When innovation is the result of interaction between ecology and stakeholders, the term "innovation ecosystem" is used to emphasize this. Other terms used the term to describe the envisaged innovation environment, while the term ecological innovation environment (e.g. many people equate creativity with innovation, and while this is understandable, it is often a mistake). The words "design" and "innovation" are often used interchangeably to describe methods for conceiving artifacts, services and systems. Although the two terms and their relationship to tools and techniques have a strong relationship to each other, they are not synonymous.

Creativity is the process of creating new innovations, and applying creativity to a new product or service is a value. Product innovations bring direct added value to the customer, while process innovations bring indirect added value to the customer by reducing costs or increasing the quality of a new or existing product. Value is generated by taking a creative new idea and moving it through a series of phases to achieve practical new innovations. In the arena of valuable and pragmatic innovation, the development of innovative products is consistent with business-centric activities and not with creative endeavours. Businessoriented activities focus on facilitating, developing and managing new and valuable products. It requires design, but it is not just about design, because design is more than just the development of a new and inventive artifact. In our field, it is useful to break down keywords in an attempt to define design and its qualifiers (design artifacts) in order to illustrate the problem of the fusion of innovation and design and to show how design influences design. Artifacts include not only the products and services we think of when we think of the "innovation", but also regulatory systems (such as business models, organizational structures and operations) that produce and deliver other artifacts as well as the legal, economic and other social systems used to organize human behaviour. It is the artifacts that people experience in the world, but it is also the artifacts that people and organizations create. The house, the iPod and the toaster are all artifacts of organizations and companies, as well as law, music and composition. Each time a new artifact is created, it not only contains physical and informative forms of its existence, but also the implicit and explicit rules through which it is experienced. The term encompasses the fully realized manifestation of atoms, bits and rules as a result of deliberate human action. Innovative activity is when a company is the focus of attention and action. The combination of heterogeneity and generativity of distributed innovation sites has led to the emergence of dynamic and non-linear patterns in digital innovation. The development and validation of analytical models to understand how 
heterogeneous actors on the edge of digital innovation networks relate to innovation patterns is an important challenge for innovation scientists. Key insights into how data analysis can facilitate innovation processes remain unexplored, especially in the context of federal networks. In this paper we want to examine this process in the context of federated networks. Such factors as the innovation processes of companies and the focus on innovations in large enterprises in industrialized countries should be taken into account. The lens of absorbance capacity defined as the two dimensions of the knowledge base comprised of knowledge diversity and the depth of links and routines can be applied, and this explains in a sense how the knowledge base of software companies influences their level of radical information technology innovation and technological breakthroughs.

Researchers who examine innovation processes from this perspective are recommended to consider the critical journey of events. Several data sources can be created, including innovation proposals, initial planning documents, progress reports, and public communications such as blogs and interviews. In addition, other materials, such as their developed artifacts, the involvement of stakeholders and workshop materials, can be used. However, only a few companies truly commit themselves to the process of continuous innovation management. This is a professional problem that affects the whole area and falls outside the competence. Management of innovations, more than any other innovation type, has enabled companies over the last 100 years to overcome new performance thresholds. The principles and processes of innovation management create long-term advantages and lead to dramatic shifts in the competitive position.

To conclude, one would probably agree with us that the turn of the millennium was marked by the rapid development of digital technologies. The ubiquity of digitalization is one of the primary forces of innovation in a variety of product and service categories. All of these defines their ability to deliver a steady stream of innovative new products and services year after year.

\section{References}

1. D. De Paoli, E. Sauer, A. Ropo, Journal of Management \& Organization, 25(2), 331-352 (2019)

2. J. Radianti, T. Majchrzak, J. Fromm, I. Wohlgenannt, Computers \& Education, 147, $103778(2020)$

3. C. Stewart, M. Bower, Educational Media International, 56(1), 14-43 (2019)

4. N. Selwyn, Digital technology and the contemporary university: Degrees of digitization (2014)

5. T. Byers, W. Imms, E. Hartnell-Young, Studies in Educational Evaluation, 58, 156-166 (2018)

6. M. Hudson, T. White, Planning Learning Spaces (2019)

7. K. Hickey, Children and Libraries, 17(3), 13-19 (2019)

8. E. Bezerra, C. Borges, T. Andreassi, International Review of Education, 63(5), 703-724 (2017)

9. R. Hadgraft, A. Kolmos, Australasian Journal of Engineering Education, 25(1), 3-16 (2020)

10. P. Čajka, L. Rýsová, Education and science and its importance in process of supporting economic growth and competitiveness in the European Union and Slovak Republic, Reality of Politics, 10(1), 11-34 (2019) 
11. M. Peschl, T. Fundneider, Journal of Organisational Transformation \& Social Change, 9(1), 41-61 (2012)

12. I. Č́belková, W. Strielkowski, A. Rybakova, A. Molchanova, International Journal of Environmental Research and Public Health, 17(7), 2177 (2020)

13. D. Sjödin, V. Parida, M. Kohtamäki, J. Wincent, Journal of Business Research, 112, 478491 (2020)

14. A. Lahiri, E. Pahnke, M. Howard, W. Boeker, Strategic Entrepreneurship Journal, 13(3), 326-358 (2019)

15. W. Strielkowski, M. Krejcí, I. Čabelková, Business: Theory and Practice 16(3), 304-315 (2015)

16. F. Osorio, L. Dupont, M. Camargo, P. Palominos, J. Peña, M. Alfaro, Creativity and Innovation Management, 28(1), 82-100 (2019)

17. P. Koudelková, P. Svobodová International Economics Letters, 3(1), 12-20 (2014)

18. M. Hartner-Tiefenthaler, K. Roetzer, G. Bottaro, M. Peschl, Thinking Skills and Creativity, 28, 21-40 (2018)

19. M. Afshar Ali, K. Alam, B. Taylor, The Information Society, 36(2), 71-96 (2020)

20. J. Becker, A. Becker, P. Sulikowski, T. Zdziebko, Procedia computer science, 126, 2173 2183 (2018)

21. Z. Li, G. Liao, K. Albitar, Business Strategy and the Environment, 29(3), 1045-1055 (2020)

22. D. Teece, Research Policy, 47(8), 1367-1387 (2018)

23. K. Vu, K. Hartley, A. Kankanhalli, Telematics and Informatics, 52, 101426 (2020)

24. C. Angeli, S. Howard, J. Ma, J. Yang, P. Kirschner, Computers \& Education, 113, 226242 (2017)

25. UNESCO, https://en.unesco.org/themes/ict-education/action (2021)

26. E. Laurent, The New Environmental Economics: Sustainability and Justice (2020)

27. S. Mehta, Millennial Asia, 9(2), 203-224 (2018)

28. R. Crescenzi, A. Rodríguez-Pose, International Journal of Urban and Regional Research, 41(6), 1010-1027 (2017)

29. G. Mulgan, Social Innovation: How societies find the power to change (2019)

30. F. Gallouj, L. Rubalcaba, M. Toivonen, P. Windrum, Industry and Innovation, 25(6), 551-569 (2018)

31. M. Davids, K. Frenken, Regional Studies, 52(1), 23-34 (2018)

32. Y. Fernando, C. Jabbour, W. Wah, Resources, Conservation and Recycling, 141, 8-20 (2019)

33. L. Kanger, J. Schot, Environmental Innovation and Societal Transitions, 32, 7-21 (2019)

34. I. De Melo-Martín, K. Intemann, The fight against doubt: How to bridge the gap between scientists and the public (2018)

35. J. Piqué, J. Berbegal-Mirabent, H. Etzkowitz, Triple Helix, 1, 1-45 (2020) 